\title{
Supramolecular Assemblies Based on Dative Boron-Nitrogen Bonds
}

\author{
Erin Sheepwash $\S^{\star}$, Burcak Icli, and Kay Severin \\ §SCS-Metrohm Foundation Award for best oral presentation
}

\begin{abstract}
Dative boron-nitrogen bonds were found to be a useful binding motif in structural supramolecular chemistry. Crystalline cages were formed using a diboronate ester and 2,4,6-tri(4-pyridyl)-1,3,5-triazine. These cages can act as hosts for electron-rich planar aromatic systems such as triphenylene. Further, crystalline two-dimensional polymers were formed via dative $\mathrm{B}-\mathrm{N}$ bonds between a triboronic ester and a ditopic pyridyl ligand. Use of an extended triboronate ester resulted in formation of a gel in toluene with a minimum gelation concentration of $0.5 \mathrm{wt} \%$.
\end{abstract}

Keywords: Boronic acids · Dative bonds · Self-assembly · Supramolecular chemistry

\section{Introduction}

Boronate esters are formed via condensation reactions of boronic acids with 1,2and 1,3-diols. Molecular nanostructures as well as materials can be accessed by combining polyboronic acids with polyalcohols. For example, molecular cages have been obtained by condensation of a cavitand-type tetraboronic acid with a dicatechol linker, ${ }^{[1]}$ or by condensation of triboronic acids with tetra-[2] and hexaols. ${ }^{[3]}$ Further, a one-dimensional polymer was synthesized by condensation of a diboronic acid with a tetraol. ${ }^{[4]}$ Two- and threedimensional polymers with interesting gas storage properties were formed by condensation of tri- or tetraboronic acids with hexahydroxytriphenylene. ${ }^{[5,6]}$

As Lewis-acidic compounds, boronate esters can form adducts with $\mathrm{N}$-donor ligands (Scheme 1). ${ }^{[7]}$ The formation of this dative boron-nitrogen bond results in a structural change at the boron atom from trigonal-planar to tetrahedral. Dative bonds between boronate esters and N-donors have been used in the context of carbohydrate sensing, ${ }^{[8,9]}$ but their utilization in structural supramolecular chemistry is less documented.[10,11] Below we show that dative $\mathrm{B}-\mathrm{N}$ bonds can be employed to construct molecular cages ${ }^{[12]}$ and polymeric networks. ${ }^{[13]}$

\section{Results and Discussion}

2,4,6-Tri(4-pyridyl)-1,3,5-triazine (tpt) has been widely used as tritopic ligand in supramolecular coordination chemistry.[14] We have chosen to combine tpt with a diboronate ester for the formation of a molecular cage. The latter was prepared by condensation of 1,4-benzenediboronic acid with 4,5-dichlorocatechol. The reac- tion of two equivalents of tpt with three equivalents of the diboronate ester resulted in the formation of the trigonal prismatic cage 1 (Scheme 2). ${ }^{[12]}$ Cage 1 displays very poor solubility, which hampered a solution-based characterization. However, it could be crystallized by dissolving it in hot dichlorobenzene $\left(\mathrm{bp} \approx 180{ }^{\circ} \mathrm{C}\right.$ ) followed by slow cooling. Presumably, the high temperature induces a rupture of the dative $\mathrm{B}-\mathrm{N}$ bonds, which are reformed upon cooling. This assumption is supported by the fact that the cage is orange in color, but dissolves in hot 1,2-dichlorobenzene to produce a nearly colorless solution.

Cage 1 features coplanar tpt ligands at a distance of approximately $7 \AA$ (Fig. 1a). When crystallized in the presence of triphenylene, we obtained a host-guest complex in which one triphenylene molecule was

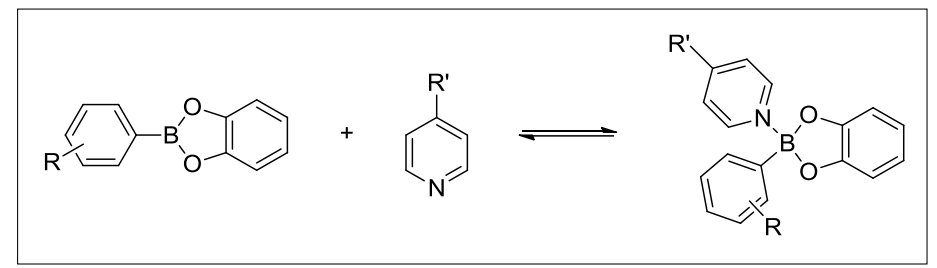

Scheme 1. Boronnitrogen dative bond formation between a dioxaborole and a pyridyl ligand.

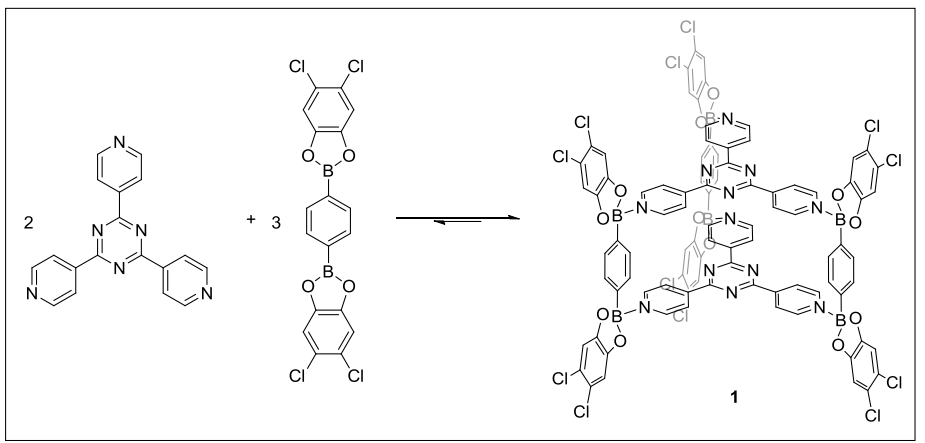

Scheme 2. Synthesis of cage 1 . 


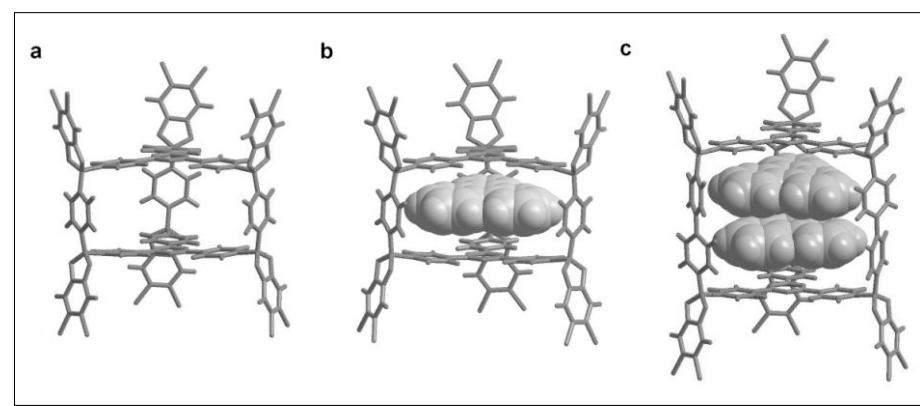

Fig. 1. Molecular structure of cage 1 (a), 1 with triphenylene encapsulated (b) and 2 with two triphenylene molecules encapsulated (c), determined by single crystal X-ray diffraction.

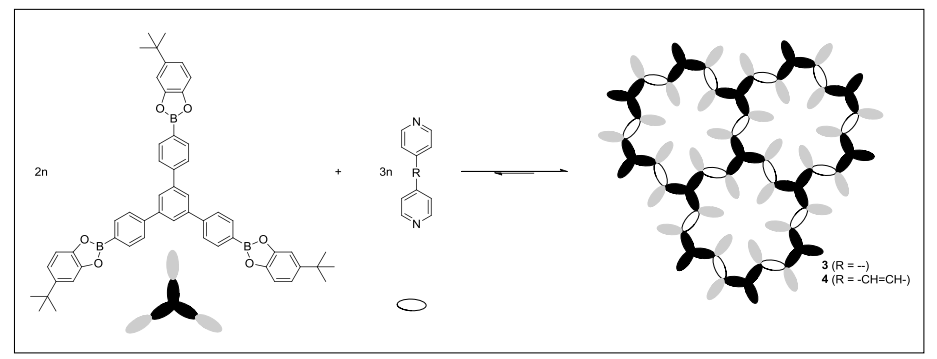

Scheme 3. Synthesis of two-dimensional networks 3 and $\mathbf{4}$

sandwiched between the tpt ligands (Fig. 1b). Coronene could be encapsulated in a similar fashion. Crystallization of a larger cage $\mathbf{2}$, which incorporated a biphenylene boronate ester, proved difficult. However, when crystallized in the presence of triphenylene, cage formation was templated to give assembly $\mathbf{2}$ with two encapsulated triphenylene molecules (Fig. 1c).

Using a similar methodology, but altering the building blocks, crystalline and soft networks could be accessed. ${ }^{[13]}$ For the formation of crystalline networks, a triboronate ester was synthesized by condensation of a triboronic acid with 4-tertbutylcatechol. Further reaction with either 4,4'-bipyridine or 1,2-di(4-pyridyl)ethylene resulted in the formation of the twodimensional networks 3 and $\mathbf{4}$ (Scheme 3 ).

The networks could be crystallized from hot toluene; as in the case of the cages, we assume that the dative B-N bonds are broken in solution. Single crystal X-ray analyses showed that $\mathbf{3}$ and $\mathbf{4}$ form twodimensional networks in which the triboronate esters are connected via the bipyridyl linkers. The polymer layers of $\mathbf{3}$ and $\mathbf{4}$ show an (A-B-C) repeat pattern in which there is no cantenation of adjacent layers although they are tightly interwoven. The crystals contain pores which are filled with solvent molecules. Thermogravimetric analyses revealed that the solvent can be removed under vacuum. However, due to the weak nature of the B-N bond, crystallinity was lost upon solvent removal. Therefore, the structures do not exhibit permanent porosity.

The synthesis of a gel was accomplished using a similar synthetic route as for the crystalline networks, but employing an extended triboronic acid derived from 1,3,5-tris (4'-bromobiphenyl)benzene. ${ }^{[15]}$ Gelation occurred when the triboronic acid was mixed in toluene with 4-tert-butylcatechol in the presence of 4,4'-bipyridine. Gel formation was possible with as little as $0.5 \mathrm{wt} \%$ of the components. The gel forms at room temperature and becomes a clear liquid upon heating due to the breakage of the dative B-N bonds. A gelation temperature of $60^{\circ} \mathrm{C}$ was determined by both NMR and UV/Vis spectroscopy. Imaging of the xerogel (obtained from toluene) by scanning electron microscopy showed a network of entangled nanofibers with diameters of less than $40 \mathrm{~nm}$.

The results summarized above demonstrate that dative $\mathrm{B}-\mathrm{N}$ bonds can be used for the formation of molecularly defined nanostructures and materials. A major drawback to these systems however, is their limited stability in solution due to the weak B-N interactions. Recently, we have performed a systematic study to evaluate the binding of boronate esters to pyridyl ligands from a thermodynamic point of view. This study revealed that electronic effects allow strengthening of the $\mathrm{B}-\mathrm{N}$ bond substantially. Using electron-poor boronate esters in combination with highly Lewisbasic pyridyl ligands we were able to achieve B-N binding constants of $10^{6} \mathrm{M}^{-1}$ or higher. ${ }^{[16]}$ These results suggest that it should be possible to construct main-chain supramolecular polymer based on dative B-N bonds. Current efforts in our laboratory aim to verify this hypothesis.

\section{Acknowledgements}

This work was supported by the Swiss National Science Foundation and by the EPFL. We thank Rosario Scopelliti and Thomas RiisJohannessen for crystallographic analyses.

Received: January 13, 2012

[1] a) N. Nishimura, K. Kobayashi, J. Org. Chem. 2010, 75, 6079; b) N. Nishimura, K. Yoza, K.
Kobayashi, J. Am. Chem. Soc. 2010, 132, 777; c) N. Nishimura, K. Kobayashi, Angew. Chem. Int. Ed. 2008, 47, 6255.

[2] H. Takahagi, S. Fujibe, N. Iwasawa, Chem. Eur J. 2009, 15, 13327 .

[3] a) K. Kataoka, S. Okuyama, T. Minami, T. D. James, Y. Kubo, Chem. Commun. 2009, 1682; b) K. Kataoka, T. D. James, Y. Kubo, J. Am. Chem. Soc. 2007, 129, 15126.

[4] W. Niu, M. D. Smith, J. J. Lavigne, J. Am Chem. Soc. 2006, 128, 16466.

[5] A. P. Cote, A. I. Benin, N. W. Ockwig, M. O'Keeffe, A. J. Matzger, O. M. Yaghi, Science 2005, 310, 1166

[6] H. M. El-Kaderi, J. R. Hunt, J. L. MendozaCortes, A. P. Cote, R. E. Taylor, M. O'Keeffe, O. M. Yaghi, Science 2007, 316, 268.

[7] H. Höpfl, J. Organomet. Chem. 1999, 581, 129.

[8] a) R. Nishiyabu, Y. Kubo, T. D. James, J. S. Fossey, Chem. Commun. 2011, 47, 1106; b) S. Franzen, W. Ni, B. Wang, J. Phys. Chem. B 2003, 107, 12942.

[9] a) B. E. Collins, S. Sorey, A. E. Hargrove, S H. Shabbir, V. M. Lynch, E. V. Anslyn, J. Org. Chem. 2009, 74, 4055; b) L. Zhu, S. H. Shabbir, V. M. Lunch, S. Sorey, E. V. Anslyn, J. Am. Chem. Soc. 2006, 128, 1222; c) W. Ni, G. Kaur, G. Springsteen, B. Wang, S. Franzen, Bioorg. Chem. 2004, 32, 571

[10] a) R. Nishiyabu, Y. Kubo, T. D. James, J. S. Fossey, Chem. Commun. 2011, 47, 1124; b) K. Severin, Dalton Trans. 2009, 5254; c) N. Fujita S. Shinkai, T. D. James, Chem.-Asian J. 2008, 3, 1076; d) H. Höpfl, Struct. Bonding 2002, 103,

[11] For examples see: a) N. Christinat, R. Scopelliti, K. Severin, Chem. Commun. 2008, 3660; b) N. Christinat, E. Croisier, R. Scopelliti, M. Cascella, U. Röthlisberger, K. Severin, Eur. J. Inorg. Chem. 2007, 5177; c) N. Christinat, R. Scopelliti, K. Severin, J. Org. Chem. 2007, 72, 2192; d) N. Christinat, R. Scopelliti, K. Severin, Chem. Commun. 2004, 1158

[12] B. Icli, E. Sheepwash, T. Riis-Johannessen, K Schenk, Y. Filinchuk, R. Scopelliti, K. Severin, Chem. Sci. 2011, 2, 1719.

[13] E. Sheepwash, V. Krampl, R. Scopelliti, O. Sereda, A. Neels, K. Severin, Angew. Chem. Int Ed. 2011, 50, 3034.

[14] a) J. K. Klosterman, Y. Yamauchi, M. Fujita, Chem. Soc. Rev., 2009, 38, 1714; b) M. Yoshizawa, J. K. Klosterman, M. Fujita, Angew. Chem., Int. Ed. 2009, 48, 3418; c) Y.-F. Han, W.-G. Jia, W.-B. Yu, G.-X. Jin, Chem. Soc. Rev. 2009, 38, 3419; d) B. Therrien, Eur. J. Inorg. Chem. 2009, 2445.

[15] J. Lu, Y. Tao, M. D'iorio, Y. Li, J. Ding, M. Day, Macromolecules 2004, 37, 2442.

[16] E. Sheepwash, M. Krause, S. Kubik, K. Severin, $\mathbf{2 0 1 2}$, in preparation. 